\title{
Zika virus and congenital malformations in perspective
}

\section{Drosten ${ }^{12}$}

1. Institute of Virology, University of Bonn, Germany

2. Deutsches Zentrum für Infektionsforschung, Bonn/Köln, Germany

Correspondence: Christian Drosten (drosten@virology-bonn.de)

Zika virus (ZIKV) has been on the agenda of virologists since many years already. Laboratories dealing with imported tropical diseases consider ZIKV infection among the differential diagnoses in cases of fever after travel to tropical Africa and Asia. The confirmation of autochthonous cases of this Old World flavivirus infection in Brazil in May 2015 was however surprising [1]. Already one month later, in June 2015 , a rapid communication in Eurosurveillance provided a hint towards the unrecognised dimension of the outbreak. The relatively inconspicuous disease had already made it to Europe by March 2015, in the blood of an Italian traveller returning from Brazil [2]. One of the possible reasons for the 'arbovirus community' to stay somewhat inert about the outbreak initially was the introduction of chikungunya virus to Central and South America about one year earlier [3]. It seemed that ZIKV was just another example of an Aedes-transmitted and primateassociated arbovirus that had made it into the virgin soil environment of the neotropics, and moreover a harmless one from a clinical perspective.

A new dimension to the emergence of ZIKV was added in October 2015, when the Brazilian Ministry of Health $(\mathrm{MoH})$ expressed concern about an increased incidence of microcephaly in newborns in the north-eastern part of the country [4]. These cases followed the assumed arrival and spread of ZIKV with a delay that made congenital infection plausible. Microcephaly had never been reported in connection with ZIKV infection before - but admittedly had not been assessed in any systematic way during previous outbreaks. In this issue of Eurosurveillance, Besnard et al. present a summary of 19 cases with a wide range of congenital cerebral abnormalities with and without microcephaly [5]. In all of these cases, the times of gestation most vulnerable for neurological fetopathies fell into the height of the 2013 to 2014 ZIKV outbreak in French Polynesia.

There is a whole number of viruses causing congenital neural malformations in humans. Cytomegalovirus, parvovirus B19 and varicella zoster virus are of highest concern in Europe. Rubella virus, the most relevant example historically, is today very rare as a cause of embryo- and fetopathy in Europe thanks to comprehensive vaccination programmes.

The threat of cerebral malformations in connection with ZIKV is difficult to express in numbers. The emotional component not only for expecting mothers and the possibility to miss a window of opportunity for study and intervention have already triggered ad hoc funding programmes and pragmatic approaches to extract information from available data [6]. It is not in spite of the emotional component, but because of it, that we should look at the problem from a rational perspective.

Most viral infections that cause fetopathy have a low manifestation index. Almost certainly, also the ZIKV will cause harm in only a small proportion of fetuses in the many pregnant women recently and currently exposed to the virus. Based mainly on data from the outbreak in French Polynesia, a recent study projected that women infected by ZIKV during the first trimester of pregnancy may have a risk of fetal microcephaly of $1 \%[6]$.

In the presently affected regions, where people are similarly exposed and immunologically naïve towards ZIKV infection, high rates of unnoticed infection are to be expected - including in pregnant women. The 6,158 suspected cases of microcephaly reported in Brazil by 9 March 2016, are likely to represent only a small fraction of the many pregnant women who got infected during 2015 [7].

Another issue is the reporting bias and classification of microcephaly. In autumn 2015, the Brazilian $\mathrm{MoH}$ strengthened and emphasised microcephaly surveillance, whereas notifications before this time occurred on a more routine basis. The media coverage of the ZIKV infection/microcephaly connection contributed an additional stimulus for reporting. A preliminary research manuscript by Rocha et al. suggests that the 
Brazilian $\mathrm{MoH}$ reporting criterion for suspected cases of microcephaly, based on cranial circumference lower than $32 \mathrm{~cm}$ at birth, might be inappropriate for the most affected population in north-eastern Brazil. In a worst case scenario raised by the authors, this criterion may trigger the formal notification of up to $10 \%$ of all newborns as suspected cases of microcephaly [8]. Of the 6,158 suspected cases notified so far, 4,249 remain under investigation [7]. Of the 1,908 cases evaluated, 1,163 have not been confirmed as cases of microcephaly [7]. There seems to be an over-notification of suspected cases of microcephaly, irrespective of ZKIV diagnosis.

The literature now contains several reports on cases with microcephaly and ZIKV detection in amniotic fluid, blood, and even central nervous tissue of fetuses with signs of microcephaly. The paper by Besnard et al. includes eight cases of microcephaly [5]. Of the five cases that were tested virologically, four yielded ZIKV by RT-PCR and maternal history was positive for symptoms compatible with ZIKV infection during pregnancy. With every new case report published, we perceive the link between ZIKV infection and microcephaly to become stronger. There is probably truth to this. However, we should remember that case reports do not establish a causative link between the virus and microcephaly. As always at the beginning of epidemics, studies tend to focus on cases but not controls. What fraction of healthy pregnancies might reveal evidence for ZIKV infection if sampled at the peak of an outbreak, assuming attack rates of $10 \%$ or even higher in the adult population? At the time of writing, 583 cases of microcephaly in Brazil have been completely investigated including objective neurological criteria and virological laboratory tests. Only $67(11.5 \%)$ were confirmed positive by laboratory tests [7].

A recent correlative analysis noted 2.8 cases of microcephaly per 10,000 births in federal states of Brazil with obvious ZIKV circulation, vs 0.6 cases per 10,000 in states without laboratory evidence for the virus [9]. These numbers suggest a 4.7 -fold increase in ZIKVaffected regions overall. In the two most affected states in the north-east, the rate was increased up to ca 18 and 24 -fold, respectively. This local concentration is remarkable. According to the latest epidemiological update by the Pan American Health Organization (PAHO), $80 \%$ of suspected cases and $97 \%$ of confirmed cases in Brazil are reported from the north-east region still. Will the incidence in other ZIKA-affected regions catch up?

The increase of microcephaly may represent a complex effect on the local population that could include other factors such as unrecognised or underdiagnosed pathogens. These factors may promote microcephaly alone or in concert with Zika virus infection. The Bulletin of the World Health Organization (WHO) Zika Open [10] carries a research manuscript that follows the incidence of microcephaly from 2012 to 2015 in Paraiba, the Brazilian federal state that was second most affected [11]. Using data from prospectively-designed birth cohorts, the study reveals a stark increase of microcephaly incidence already by end of 2012 and a second peak by mid-2014. Neither of the peaks can be explained by the presumed introduction of ZIKV by mid of 2014. A third peak of incidence recorded for the second half of 2015 is the strongest peak. Only this peak plausibly correlates with Zika outbreaks. We should remain open for additional explanations for the increased incidence of microcephaly observed in north-eastern Brazil.

Also, beyond microcephaly, we should not forget other neurological symptoms and malformations. Besnard et al. demonstrate that ZIKV infection was not confirmed in any of the 11 cases with non-microcephalic abnormalitities [5]. However, another recent study found a number of non-microcephalic cerebral malformations in fetuses and newborns with signs of ZIKV infection [12]. Much more worrying with regard to numbers is the perspective of sequelae, due to impairment of the central nervous system, in form of deficits that may come to show as children develop. The available reports on fetal neurotropic infection call for neuro-psychiatric follow-up of birth cohorts.

Most countries in Middle America seem to be over their recent peak of incidence of ZIKV infections by now, March 2016. We will thus be able to observe over the next coming months whether the incidence of microcephaly will increase in these areas that have been newly affected by ZIKV since the end of 2015. Animal experiments conducted to provide evidence of causation of microcephaly may unfortunately not be concluded earlier than observations in humans. It is our responsibility as public health scientists to secure epidemiological evidence by careful design of prospective, controlled observational trials. Until we have results, it should not make a difference whether exposure prophylaxis is implemented based on evidence, or out of an abundance of caution.

\section{Conflict of interest}

None declared.

Authors' contributions

Christian Drosten wrote the editorial.

\section{References}

1. Kindhauser MK, Allen T, Frank V, Santhana RS, Dye C. Zika: the origin and spread of a mosquito-borne virus [Submitted]. Bull World Health Organ. E-pub: 9 Feb 2016.

2. Zammarchi L, Tappe D, Fortuna C, Remoli ME, Günther $S$, Venturi $G$, et al. Zika virus infection in a traveller returning to Europe from Brazil, March 2015. Euro Surveill. 2015;20(23):21153. DOI: $10.2807 / 1560-7917 . E S 2015 \cdot 20.23 \cdot 21153$ PMID: 26084316

3. Leparc-Goffart I, Nougairede A, Cassadou S, Prat C, de Lamballerie X. Chikungunya in the Americas.Lancet. 
2014;383(9916):514. DOI: 10.1016/S0140-6736(14)60185-9 PMID: 24506907

4. Pan American Health Organization (PAHO) / World Health Organization Regional Office for the Americas (WHO). Epidemiological Alert. Increase of microcephaly in the northeast of Brazil. Washington D.C.: PAHO/WHO 2016. Available from: http://www.paho.org/hq/index. php?option=com_docman\&task=doc_view\&Itemid=270\&gid= 32285\&lang $=$ en

5. Besnard $M$, Eyrolle-Guignot $D$, Guillemette-Artur $P$, Lastère S, Bost-Bezeaud F, Marcelis L, et al. Congenital cerebral malformations and dysfunction in fetuses and newborns following the 2013 to 2014 Zika virus epidemic in French Polynesia. Euro Surveill. 2016;21(13):30181. DOI: $10.2807 / 1560$ 7917.ES.2016.21.13.30181

6. Cauchemez S, Besnard M, Bompard P, Dub T, Guillemette-Artur $P$, Eyrolle-Guignot D, et al. Association between Zika virus and microcephaly in French Polynesia, 2013-15: a retrospective study. Lancet. 2016 Mar 15. pii: So140-6736(16)oo651-6. [Epub ahead of print]

7. Pan American Health Organization / World Health

Organization. Zika Epidemiological Update - 09 March 2016. Washington D.C.: PAHO/WHO; 2016.

8. Rocha HAL, Correia LL, Leite AJM, Campos IS, Cavalcante e Silva A, Machado MMT, et al. Microcephaly: normality parameters and its determinants in northeastern Brazil: a multicentre prospective cohort study [Submitted]. Bull World Health Organ. E-pub. 2016. DOI: 10.2471/BLT.16.171215

9. Kleber de Oliveira W, Cortez-Escalante J, De Oliveira WT, do Carmo GM, Henriques CM, Coelho GE, et al. Increase in Reported Prevalence of Microcephaly in Infants Born to Women Living in Areas with Confirmed Zika Virus Transmission During the First Trimester of Pregnancy - Brazil, 2015. MMWR Morb Mortal Wkly Rep. 2016;65(9):242-7. DOI: 10.15585/mmwr. mm6509e2 PMID: 26963593

10. The Bulletin of the World Health Organization (WHO). Zika Open. Geneva: WHO; 2016. Available from: http://www.who. int/bulletin/online_first/zika_open/en/http://

11. Soares de Araújo JS, Regis CT, Gomes RGS, Tavares TR, Rocha dos Santos C, Assunção PM, et al. Microcephaly in northeast Brazil: a review of 16208 births between 2012 and 2015 [Submitted]. Bull World Health Organ. E-pub. 2016.DOI: 10.2471/BLT.16.170639

12. Brasil P, Pereira JP Jr, Raja Gabaglia C, Damasceno L, Wakimoto M, Ribeiro Nogueira RM, et al. Zika Virus Infection in Pregnant Women in Rio de Janeiro -Preliminary Report. N Engl J Med. 2016 Mar 4. [Epub ahead of print] .PMID: 26943629

\section{License and copyright}

This is an open-access article distributed under the terms of the Creative Commons Attribution (CC BY 4.0) Licence. You may share and adapt the material, but must give appropriate credit to the source, provide a link to the licence, and indicate if changes were made.

This article is copyright of the authors, 2016. 